\title{
Comparing Local Analysis and Prediction System (LAPS) Assimilations with Independent Observations
}

\author{
Christopher A. Hiemstra \\ Department of Atmospheric Science, Colorado State University, Fort Collins, Colorado \\ GLEN E. LISTON \\ Cooperative Institute for Research in the Atmosphere, Fort Collins, Colorado \\ Roger A. Pielke Sr. \\ Department of Atmospheric Science, Colorado State University, Fort Collins, Colorado \\ DANIEL L. BIRKENHEUER \\ NOAA/Earth System Research Laboratory, Boulder, Colorado \\ Steven C. Albers \\ Cooperative Institute for Research in the Atmosphere, Fort Collins, Colorado, and NOAA/Earth System Research Laboratory, \\ Boulder, Colorado
}

(Manuscript received 18 October 2005, in final form 4 April 2006)

\begin{abstract}
Meteorological forcing data are necessary to drive many of the spatial models used to simulate atmospheric, biological, and hydrological processes. Unfortunately, many domains lack sufficient meteorological data and available point observations are not always suitable or reliable for landscape or regional applications. NOAA's Local Analysis and Prediction System (LAPS) is a meteorological assimilation tool that employs available observations (meteorological networks, radar, satellite, soundings, and aircraft) to generate a spatially distributed, three-dimensional representation of atmospheric features and processes. As with any diagnostic representation, it is important to ascertain how LAPS outputs deviate from a variety of independent observations. A number of surface observations exist that are not used in the LAPS system, and they were employed to assess LAPS surface state variable and precipitation analysis performance during two consecutive years (1 September 2001-31 August 2003). LAPS assimilations accurately depicted temperature and relative humidity values. The ability of LAPS to represent wind speed was satisfactory overall, but accuracy declined with increasing elevation. Last, precipitation estimates performed by LAPS were irregular and reflected inherent difficulties in measuring and estimating precipitation.
\end{abstract}

\section{Introduction}

The use of meteorological forcing data to drive land surface/hydrological models is an active area of investigation. Advances in Land Data Assimilation Systems (LDAS) at global (Rodell et al. 2004) and continental

\footnotetext{
Corresponding author address: Dr. Christopher A. Hiemstra, Cooperative Institute for Research in the Atmosphere, Colorado State University, 1375 Campus Delivery, Fort Collins, CO 80523-1375.
} E-mail: hiemstra@cira.colostate.edu scales (Mitchell et al. 2004) have illustrated the utility of merging atmospheric and surface process models. Similar studies are needed at local and regional scales.

Gridded local and regional meteorological fields are necessary to drive many of the spatial models used to simulate river discharge and floods (e.g., Jasper et al. 2002; Westrick et al. 2002), ecosystem processes (e.g., Running and Coughlan 1988; Scuderi et al. 1993; Parton et al. 1998), snow distributions (e.g., Liston and Sturm 2002; Winstral et al. 2002; Liston and Elder 2006a), and hydrologic cycle processes (e.g., Ludwig and Mauser 
2000; Whitaker et al. 2003). Unfortunately, many areas (e.g., high-elevation mountains, intermountain shrublands, deserts, and sparsely populated areas) lack meteorological observations. Furthermore, available point observations are not always suitable for landscape or regional applications (Pielke et al. 2002), especially in forested and mountainous regions.

A remedy for generating local and regional weather observations involves the assimilation of available meteorological data into spatial and temporal diagnoses. One approach, used at local scales, is to distribute observed meteorological variables over the domain of interest, in most cases utilizing topographic variation as a controlling factor (e.g., Thornton et al. 1997; Liston and Elder 2006b). At coarser scales, mesoscale data assimilation and forecast systems that incorporate a wide variety of data are available and widely used (see Lazarus et al. 2002 for an overview). However, more information on the strengths and shortcomings of potential meteorological data is desirable before incorporating assimilations into models.

The focus of this paper, the National Oceanic and Atmospheric Administration's (NOAA) Local Analysis and Prediction System (LAPS; information available online at http://laps.fsl.noaa.gov/) generates local- to regional-scale gridded atmospheric forcing fields for land surface/hydrologic models. LAPS is a mesoscale meteorological data assimilation tool that employs a suite of observations (meteorological networks, radar, satellite, soundings, and aircraft) to generate a realistic, spatially distributed, time-evolving, three-dimensional representation of atmospheric features and processes (McGinley et al. 1991; Albers 1995; Albers et al. 1996; Birkenheuer 1999). Analyses produced by LAPS include wind speed, wind direction, surface temperature, relative humidity, surface pressure, precipitation, and cloud cover. Because LAPS produces a spatially distributed representation of meteorological observations, it provides important opportunities for users who require local (10 $\mathrm{km}$ or finer horizontal grid increment) meteorological data to drive distributed land surface and ecosystem models over local to regional domains. In addition, LAPS can be used to provide an up-to-date atmospheric state representation for nowcasting and assessment, and it can serve as a mechanism to initialize localscale mesoscale weather forecast models.

To determine its suitability for various assessment and modeling applications, it is important to ascertain how LAPS outputs deviate from independent observations. Most readily available observations (e.g., National Weather Service, various state-level departments of transportation, and Federal Aviation Administration weather) are integrated into LAPS; therefore, they can- not be used to assess performance. However, observations collected by networks not used in LAPS are convenient sources of validation data that can be used to apply a more rigorous test than data denial.

Our study is motivated by two primary concerns. First, how well are daily and seasonal trends represented in assimilations? Second, what are the differences between assimilations and independent observations? By addressing these concerns, we hope to identify strengths and shortcomings associated with LAPS outputs. Our objective is to employ independent meteorological data to examine relationships among LAPS assimilations and observed data with respect to meteorological variables commonly used as terrestrial model drivers: temperature, relative humidity, wind speed, and precipitation. Our goal is to examine how LAPS data relate to coincident observations from the perspective of a LAPS end user.

\section{Study area}

The $1312500 \mathrm{~km}^{2}(1250 \mathrm{~km} \times 1050 \mathrm{~km})$ LAPS domain encompasses the states of Colorado, Wyoming, and portions of South Dakota, Nebraska, Kansas, Oklahoma, New Mexico, Arizona, Utah, Idaho, and Montana (Fig. 1). The weather, topography, and land cover of the domain are typical of the Great Plains (Sims and Risser 2000) and Rocky Mountain (Peet 2000) regions. The weather is continental and dry with relatively high summer and low winter temperatures. The landforms shift from the eastern edge of the flat and rolling plains and tablelands to the western canyons and high peaks of the Rocky Mountain Cordillera. As a reflection of the interaction between atmosphere and land surface, the land cover changes from agricultural cropland, pastures, and grasslands in the east to mountain forests and shrubland basins in the west.

\section{Methods}

Validation of LAPS assimilations required hourly LAPS data, independent meteorological observations, meteorological station site characteristics, and statistical analyses. LAPS validations were performed for assimilations spanning the 2-yr period of 1 September 2001-31 August 2003 over the domain of interest (Fig. 1).

\section{a. LAPS assimilations}

LAPS, developed and operated by NOAA's Earth System Research Laboratory in Boulder, Colorado, combines a wide array of observed meteorological datasets into a unified atmospheric analysis with a time interval of an hour or less. An analysis contains both 


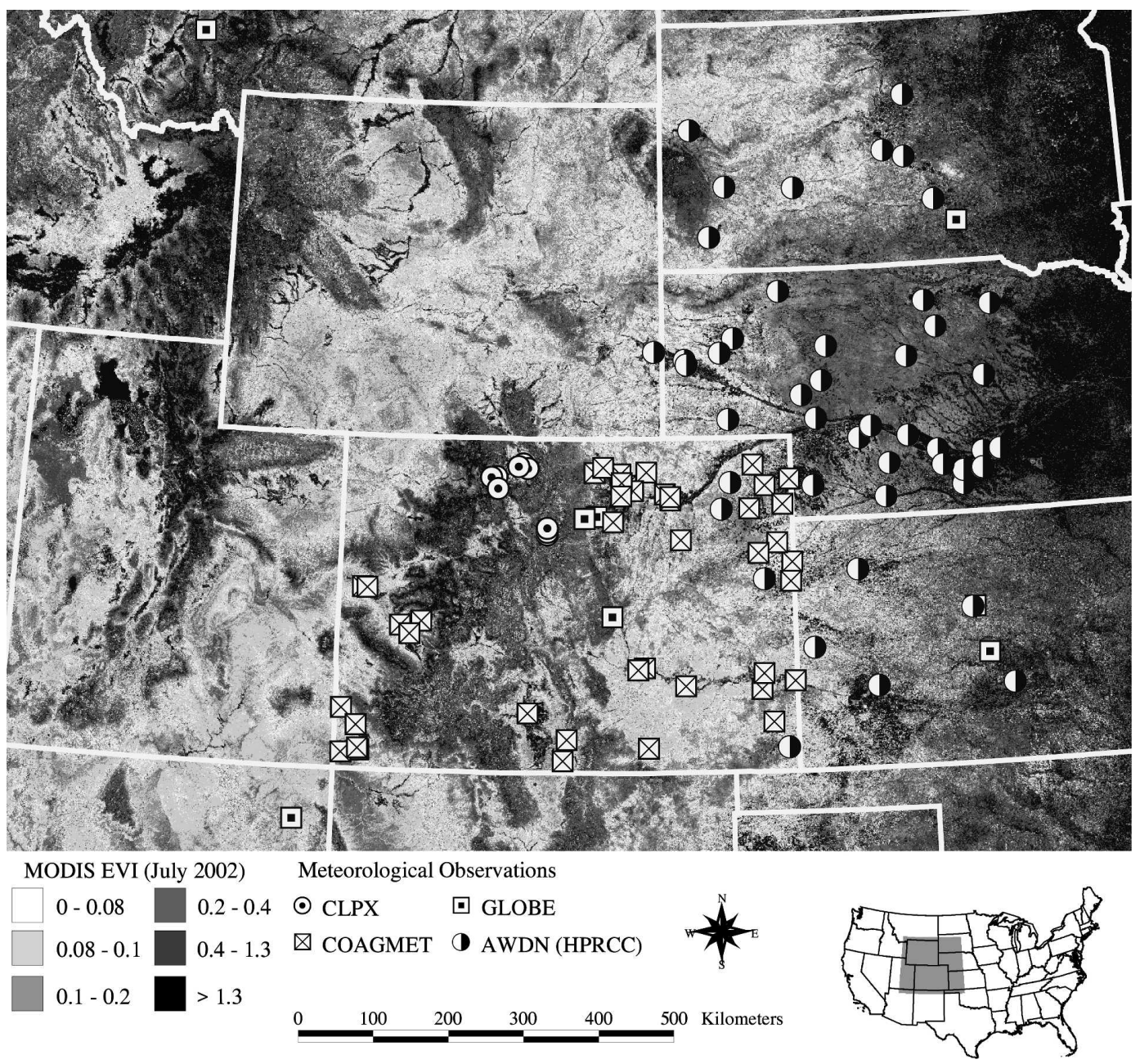

FIG. 1. The LAPS domain, portrayed in this Moderate Resolution Imaging Spectroradiometer enhanced vegetation index image, envelops CO, WY, and portions of the surrounding states. Data used for validation include CLPX, COAGMET, GLOBE, and the HPRCC's AWDN.

spatially and temporally continuous atmospheric state variables in addition to special atmospheric and landbased fields over Colorado, Wyoming, and portions of the surrounding states (Fig. 1). The quasi-operational analyses data used in the study described herein employ a $10-\mathrm{km}$ horizontal grid $(125 \times 105)$ with 21 isobaric vertical levels and hourly temporal resolution (Liston et al. 2006, manuscript submitted to J. Hydrometeor.).

\section{1) DRIVING DATA}

LAPS employs a wide range of observational datasets to construct its diagnoses, including 1) surface observations from regional surface networks every 5 min to $3 \mathrm{~h}, 2$ ) hourly surface aviation observations, 3 ) Doppler radar volume scans every 6-10 min, 4) wind and temperature Radio Acoustic Sounding System profiles from the NOAA Demonstration Profiler Network every 6-60 $\mathrm{min}, 5$ ) satellite visible data every $15-30$ min, 6) multispectral image (e.g., Geostationary Operational Environmental Satellite) and sounding radiance data every $60 \mathrm{~min}, 7)$ global positioning system total precipitable water vapor determined from signal delay, and 8) automated aircraft observations.

LAPS topography and land surface is based on 1-km grid increment U.S. Geological Survey (USGS) land use data (Loveland et al. 2000) that provides 24 land application and vegetation-type categories along with the basis for discerning water-land fraction in the domain.

\section{2) Analyses}

Temperature, relative humidity (from dewpoint), and wind speed are calculated using LAPS surface fields analyses, which were initially described by McGinley et al. (1991). Since then, the procedure has been revised and is described here with particular at- 
tention to temperature $T$, dewpoint Td, and wind $U$ and $V$. The surface field creation process entails data ingestion, the development of background fields, and successive correction. The analysis is designed to operate in situations of rough terrain, nonuniform station spacing, and it incorporates instrument errors and firstguess fields. Dynamical and terrain-related structures from a downscaled first guess are retained by performing the analysis in increment space.

LAPS starts with a 3D first-guess or background field interpolated to the $10-\mathrm{km}$ grid from a large-scale forecast model output. For this work, the 40-km Rapid Update Cycle forecasts (Benjamin et al. 2004a; Benjamin et al. 2004b) were used, but LAPS can operate with other models [e.g., the Eta Model, now known as the North American Mesoscale model (Black 1994), and the Aviation Model, now known as the Global Forecast System model (Kanamitsu 1989)]. Because the background model terrain is on a coarser grid than LAPS, downscaling is performed so that the processed fields have reasonably finescale terrain-related structure. The downscaling process uses horizontal bilinear interpolation, and vertical interpolation is used to create the finer grid scales for fields such as temperature and dewpoint. For example, temperature downscaling is accomplished by using a locally determined lapse rate and elevation differences to adjust the coarser, initial 3D first-guess surface temperature field to the finerresolution LAPS topography. Downscaled wind fields are calculated by vertically interpolating the 3D LAPSanalyzed wind field (Albers 1995) to the surface topography.

Prior to the analysis of each field, several quality control steps are performed. First, observations outside of climatologically expected values are rejected. Second, observations that deviate from the background field by more than a threshold value are omitted. A final test compares the increments of the remaining observations to a dynamically determined threshold, which is proportional to the standard deviation of the observation increments and a proportionality constant dependent on the field.

After the quality control is completed, the analysis is initiated and a telescoping successive correction is done to improve the fit between the observations and background fields. After each iteration, the outcome becomes the background field for the next iteration. During each successive correction procedure, a modified Barnes scheme is employed to weigh and blend observation increments with the updated background field until appropriate finescale structure is developed. Observation increments are given weights according to instrument and representativeness errors. The back- ground at each grid point is given an "observation" increment of zero with an appropriate weight corresponding to the background error. This strategy allows the analysis to smoothly trend toward the background in data-sparse regions. The iterations continue until the finescale structure and fit to observations become commensurate with observation spacing and instrument error. Further, the analysis is constrained to vary from the background by no more than the magnitude of the observation rejection threshold discussed above. This helps prevent overshooting (ballooning) of gradients into data-sparse areas. A variational minimization is done as a final step to enforce dynamical consistency between the wind and pressure fields.

During each step in the analysis process, elevation and land surface characteristics are also considered. Because LAPS uses a 10-km horizontal grid increment, substantial differences in observed station elevation and the LAPS gridded terrain field can exist. To correct for this difference and its effects on temperature and dewpoint, $T$ and $\mathrm{Td}$ observations are corrected using standard lapse rates during each surface analysis.

The land surface data are used to determine a landwater mask for the analyses. The land fraction term prevents situations where heating and frictional effects over land surfaces have undue effects over water with respect to $T, \mathrm{Td}, U$, and $V$ fields.

LAPS precipitation analyses provide quantitative estimates of liquid precipitation derived from various types of radar data. For the version used in this study, low-level mosaics of Weather Surveillance Radar-1988 Doppler reflectivity were used as supplied by WSI's NOWrad. Precipitation analyses used for this comparison were described by Albers et al. (1996).

\section{3) Comparison PREPARATION}

Preparation for the comparison involved extracting LAPS data from the LAPS grid point nearest the independent meteorological stations. Additional processing was not employed for the hourly comparisons, but for daily comparisons, LAPS data were aggregated to daily maximums, minimums, and averages.

\section{b. Independent meteorological observations}

Validation of the LAPS diagnoses required comparison with meteorological data not used in the LAPS analyses. Such datasets are routinely collected by educational and agricultural observational networks and field experiment campaigns, and they are easily accessible. Independent data sources utilized for validation included a total of 107 stations from the Cold Land Processes Experiment (CLPX; Cline et al. 2002), Colorado Agricultural Meteorological Network 
TABLE 1. Description of the meteorological instruments and measurement heights used as independent observations.

\begin{tabular}{|c|c|c|c|c|}
\hline Source & Temperature $\left({ }^{\circ} \mathrm{C}\right)$ & RH (\%) & Wind speed $\left(\mathrm{m} \mathrm{s}^{-1}\right)$ & Precipitation (mm) \\
\hline \multicolumn{5}{|c|}{ CLPX } \\
\hline Instrument & Vaisala HMP45C probe & $\begin{array}{l}\text { Vaisala HMP } 45 \mathrm{C} \\
\text { probe }\end{array}$ & $\begin{array}{l}\text { R.M. Young } 05103 \\
\text { anemometer }\end{array}$ & Various (not used) \\
\hline Measurement height (m) & 10 & 10 & 10 & - \\
\hline \multicolumn{5}{|c|}{ COAGMET } \\
\hline Instrument & Vaisala HMP45C probe & $\begin{array}{l}\text { Vaisala } \mathrm{HMP} 45 \mathrm{C} \\
\text { probe }\end{array}$ & $\begin{array}{l}\text { R.M. Young } 05103 \\
\text { anemometer }\end{array}$ & $\begin{array}{l}\text { TE525 tipping-bucket } \\
\text { gauge (not heated) }\end{array}$ \\
\hline Measurement height (m) & 1.5 & 1.5 & 3 & $>1$ \\
\hline \multicolumn{5}{|c|}{ GLOBE } \\
\hline Instrument & $\begin{array}{l}\text { Max and min } \\
\text { thermometer (various) }\end{array}$ & - & - & $\begin{array}{l}\text { Plastic rain gauge collector } \\
>102 \mathrm{~mm} \text { diam }\end{array}$ \\
\hline Measurement height (m) & 1.5 & - & - & $0.5-1.7$ \\
\hline \multicolumn{5}{|c|}{ HPRCC AWDN } \\
\hline Instrument & $\begin{array}{l}\text { Vaisala HMP35 and } \\
\text { HMP45 }\end{array}$ & $\begin{array}{l}\text { Vaisala HMP35 and } \\
\text { HMP45 }\end{array}$ & $\begin{array}{l}\text { MET-One } 014 \\
\text { anemometer }\end{array}$ & Tipping bucket (various) \\
\hline Measurement height (m) & 1.5 & 1.5 & 3 & $0.5-1$ \\
\hline
\end{tabular}

(COAGMET; information online at http://ccc.atmos. colostate.edu/ coagmet/), the Global Learning and Observations to Benefit the Environment (GLOBE) Program (http://www.globe.gov/), and the High Plains Regional Climate Center's (HPRCC's) Automatic Weather Data Network (AWDN; http://www.hprcc. unl.edu/awdn/).

Validation sources possessed a range of observed variables, temporal resolutions, and measurement heights (Table 1). Automated stations (CLPX, COAGMET, and AWDN) monitored air temperature, relative humidity, wind speed, and precipitation. GLOBE data included temperature and precipitation measurements. Observations ranged in frequency from $10 \mathrm{~min}$ (CLPX) to daily (GLOBE); the remaining sources performed hourly measurements. Because CLPX data were observed at a finer resolution than LAPS assimilations, they were averaged to hourly observations. Comparisons using GLOBE data involved aggregating LAPS data to a daily time step. Most measurement heights were 1.5 and $3 \mathrm{~m}$; CLPX data were collected at $10 \mathrm{~m}$. After the data were collected, MicroMet preprocessor (Liston and Elder 2006b) quality control measures were employed to find values outside of acceptable limits, consecutive values changing too rapidly, or repeating consecutive values.

\section{c. Station site characteristics}

\section{1) Elevation}

LAPS and station elevation differences were a concern during validation. Because LAPS assimilations were performed at $10-\mathrm{km}$ horizontal grid increments, observed differences in LAPS diagnoses and observations required consideration, especially in mountainous terrain. Thus, station elevations were subtracted from LAPS elevation to yield elevation differences that were used to assess potential LAPS elevation representation errors. Further, the effect of elevation on our comparison results was considered.

\section{2) DistANCE FROM NEAREST LAPS-USED METEOROLOGICAL DATA}

Most of the independent meteorological observations employed in this validation are operated for agricultural purposes. Thus, there is a bias in this dataset (Fig. 1) toward relatively low-elevation, grassland or cropland sites, some of which were unavoidably located near data sources employed in LAPS [e.g., routine aviation weather reports (METARs) and radar]. This is an important, but unavoidable, limitation given the large number of data sources employed in LAPS. However, relatively remote observation (e.g., CLPX and some COAGMET and AWDN) stations were also employed for validation. To assess the potential proximity effect on our validation, the nearest distance between independent observations and LAPS-used stations was calculated using geographic information system (GIS).

\section{3) LAND COVER}

Spatial data were also necessary to perform the LAPS validation with respect to variations in land cover and elevation within the domain (Fig. 1). Land surface characteristics have been shown to influence local weather characteristics and diurnal fluctuations 
(Pielke et al. 2000; Pielke et al. 2003). We also desired to identify and assess the potential influence of land cover on the errors associated with LAPS assimilations and observed data.

A 30-m grid interval National Land Cover Dataset (NLCD; Vogelmann et al. 2001) was obtained from the USGS Seamless Data Distribution System for the entire LAPS domain (Fig. 1). Because we wanted to accurately represent the predominant land-cover type associated with each station, the $30-\mathrm{m}$ resolution NLCD was resampled to $1 \mathrm{~km}$, station coordinates were intersected with the 1-km NLCD data in GIS, and each independent observation site was attributed with a predominant land-cover class.

\section{d. Statistical analyses}

The LAPS validation process occurred in two principal steps. In the first step, LAPS air temperature, relative humidity, wind speed, and precipitation data were contrasted with observations using three methods. First, LAPS values were compared with observations using simple linear regressions. Second, because diurnal and seasonal trends are inherent in LAPS and observed datasets, a more absolute metric, root-mean-square error (rmse), was employed to quantify differences between LAPS and observed variables. Last, daily ranges (maximum-minimum) of the four LAPS and observed variables were compared with observations using simple linear regressions as a more rigorous test of LAPS's ability to represent daily extremes.

The second step entailed the assessment of observed versus modeled relationships identified in the first stage with respect to observation site characteristics (station elevation, independent-station distance from nearest LAPS-assimilated data, and land cover). With the exception of land cover, site characteristics were regressed against temperature, relative humidity, wind speed, and precipitation measures (i.e., $r^{2}$ comparisons, rmse, and daily range $r^{2}$ values) using simple linear regressions. To evaluate the role of land cover, one-way analysis of variance (ANOVA) was performed using the temperature, relative humidity, wind speed, and precipitation estimates of variance $\left(r^{2}\right)$ as the response and land-cover class as the factor (Minitab 2000). Tukey's one-way multiple comparisons (family rate $=$ $0.05)$ were employed to assess differences in $r^{2}$ among the cover types.

\section{Results and discussion}

\section{a. Simple linear regressions}

Simple linear regressions of LAPS assimilations versus observations of temperature, relative humidity, wind speed, and precipitation illustrated the abilities of LAPS to represent the four examined meteorological properties (Fig. 2a). The linear regressions performed on $2 \mathrm{yr}$ of temperature and relative humidity data from 107 and 99 stations, respectively, indicated that much of the variation in observed data is duplicated in LAPS assimilations. The mean $r^{2}$ values associated with temperature and relative humidity analyses were 0.96 and 0.82 , respectively. The variation represented by most equations with respect to LAPS and observed wind speeds (99 stations) was intermediate overall; the mean regression $r^{2}$ value was 0.50 . For precipitation, the average of 96 station $r^{2}$ values was the poorest among the compared meteorological variables (0.32).

In addition to having the highest average $r^{2}$ value, the range of temperature $r^{2}$ values was also relatively small, ranging from 0.64 to 0.99 (Fig. 2a), compared with the other meteorological variables. In most cases, the temperature comparison $r^{2}$ values were similar among the examined stations. Relative humidity $r^{2}$ values were from 0.45 to 0.95 . In contrast, wind speed (0.01-0.85) and precipitation $(0.01-0.76) r^{2}$ values possessed larger ranges, indicating a substantial variation in agreement among the stations.

\section{b. The rmse values}

While linear regressions indicated how well LAPS followed observed trends on an hourly basis, more information about the absolute difference is desired. The rmse values indicated the mean unit difference between hourly LAPS assimilation values and their coincident hourly observations (Fig. 2b). Overall, temperature and relative humidity rmse values were $1.9^{\circ} \mathrm{C}$ and $9 \%$, respectively. Wind speed average rmse values were 1.7 $\mathrm{m} \mathrm{s}^{-1}$. Precipitation rmse values had an average difference of $0.69 \mathrm{~mm}$. Considering the different measurement units, the narrowest minimum to maximum difference in rmse values was associated with wind speed. In contrast, the highest rmse range was found with precipitation.

\section{c. Daily range regressions}

Comparisons of daily extremes highlighted how well LAPS represented the magnitude of daily changes (Fig. $2 c)$. Temperature and relative humidity range agreements between LAPS and observed data indicated a poorer fit than the hourly comparisons. Average temperature and relative humidity $r^{2}$ values were 0.63 and 0.5 , respectively. The average proportions of variability in LAPS versus observed wind speed (35\%) and precipitation were similar (39\%). Given the number of sources from which LAPS draws data and the $10-\mathrm{km}$ 

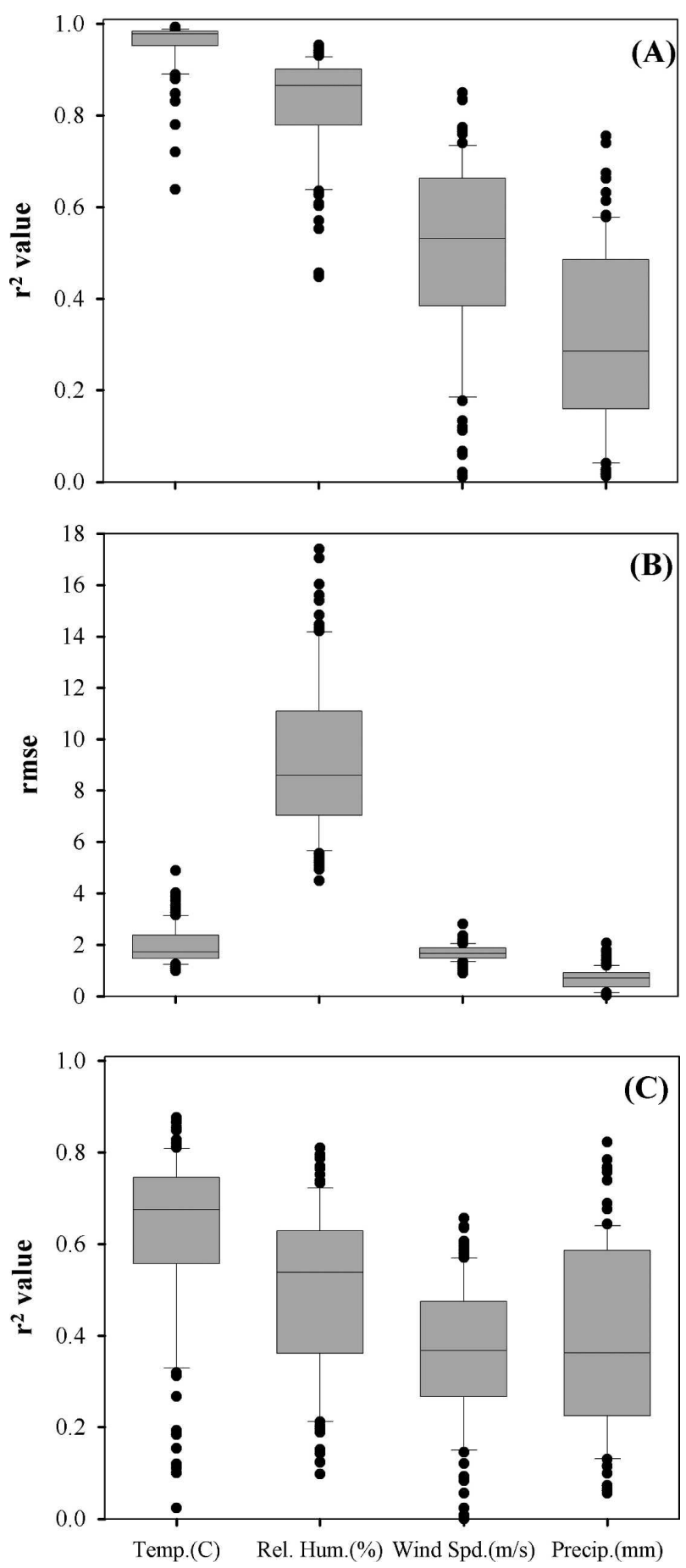

FIG. 2. LAPS assimilations and observed comparisons were made using direct linear regressions, summarized by (a) $r^{2}$ values, (b) rmse, and (c) linear regressions of diurnal ranges. The box plots display the median (solid line), and 10th, 25th, 75th, and 90th percentiles of the $r^{2}$ and rmse values. resolution at which LAPS functions, it is not surprising that the agreement between observed and LAPS diurnal extremes was poorer than the hourly comparisons.

\section{d. Vineland, Colorado, case study}

While linear regressions and rmse values provided a general and rigorous test of how well the LAPS assimilations represented the examined meteorological conditions among a number of distinct locations, more investigation into the comparisons at specific locations is preferred. However, presenting linear regressions performed on 107 datasets of hourly temperature, relative humidity, wind speed, and precipitation over a period of $2 \mathrm{yr}$ is not practical. Instead, a station located in the high plains grassland of southeastern Colorado $\left(38.271^{\circ} \mathrm{N}, 104.467^{\circ} \mathrm{W}\right)$ and operated by the Colorado Agricultural Meteorological Network (2003) was selected to more thoroughly assess LAPS assimilations against observations with respect to diurnal and seasonal cycles. The Vineland station exhibited median hourly regression $r^{2}$ values for all four examined variables and it is located $7 \mathrm{~km}$ from the nearest METAR data (Pueblo Memorial Airport) used in LAPS. Comparing the observations with LAPS diagnoses on an hourly time scale is easily done by coincidently plotting the values and examining the individual linear regression plots for the stations.

\section{1) Temperature}

Temperature values were nearly identical in the LAPS assimilations compared with the independent observations associated with the Vineland, Colorado, site (Fig. 3). In the plots, few temporal lags exist and not many differences between the two plots are discernable during the three examined months. Afternoon temperatures were highest while nighttime and morning temperatures were lower. Autumn, winter, and spring (Figs. 3a-c) diurnal patterns and temperature extremes are represented in both records; few LAPS data points deviate substantially from the observed record, and differences are most frequently associated with daily minimum and maximum temperatures.

The simple linear regression performed on the LAPS and observed records (Fig. 3d) indicated that agreement was high $\left(r^{2}=0.98\right)$ and the slope of the equation approximated a 1:1 relationship. Furthermore, the cluster of compared points shows a small level of variation around the 1:1 regression line and a $y$ intercept close to 0 , indicating that there were no clear errors with respect to temperature and few differences between LAPS and observed data. The rmse value was representative of all 

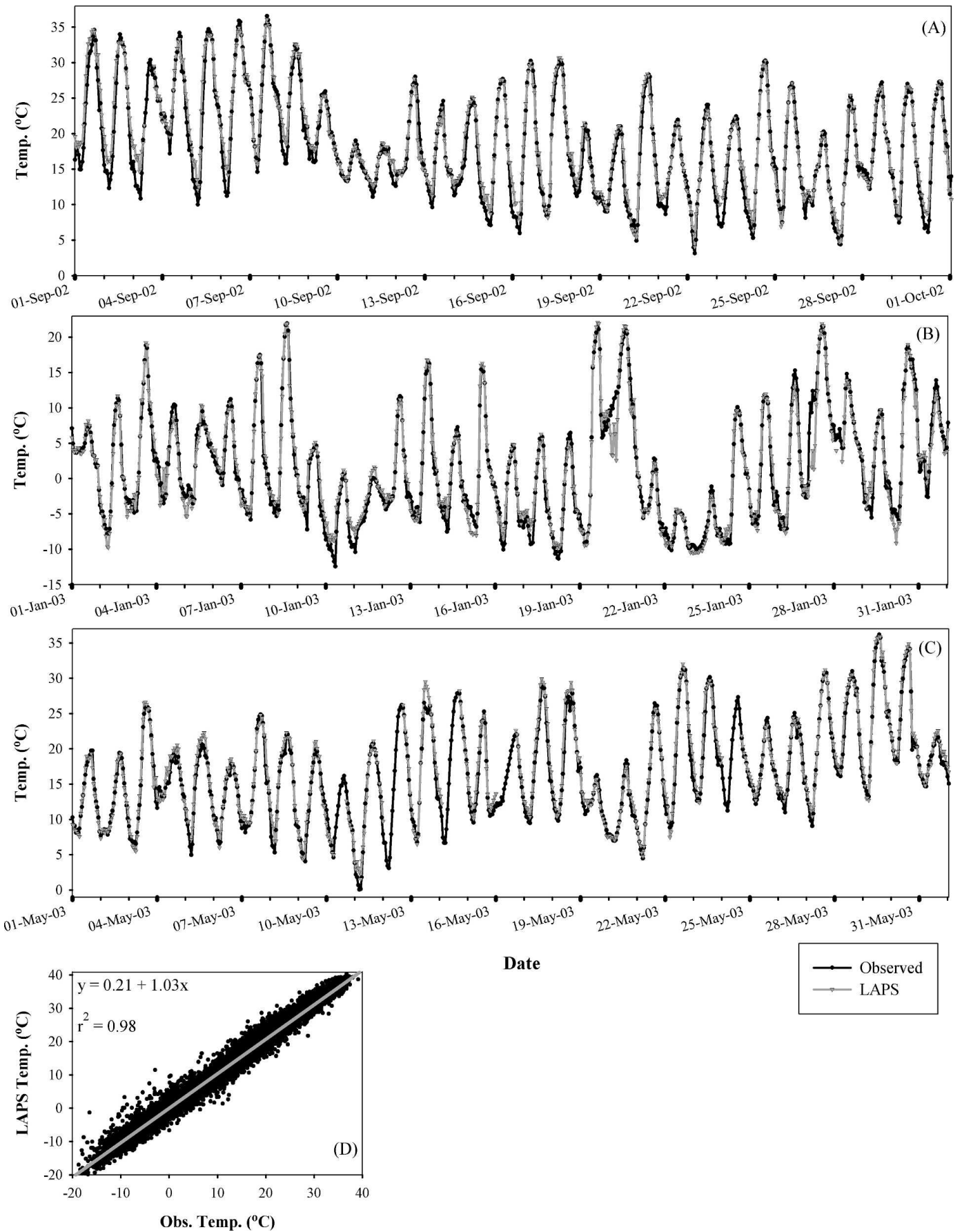

Date

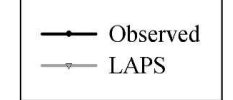

FIG. 3. Vineland, CO, LAPS air temperature assimilations are shown compared with simultaneous observations during (a) Sep 2002, (b) Jan 2003, and (c) May 2003. (d) A simple linear regression for all comparisons from 1 Sep 2001 through 31 Aug 2003.

sites (1.8), as was the $r^{2}$ value (0.66) of the temperature range regression (Figs. 2b,c).

Why was air temperature so well represented in LAPS? Air temperature is a continuous variable that varies relatively smoothly through time and space in most conditions, and these changes tend to be moderate and predictable based on characteristics of atmospheric dynamics, elevation (Pielke and Mehring 1977), and land surface characteristics [vegetation, soil moisture, etc. (Marshall et al. 2004a,b)]. The LAPS assimi- 

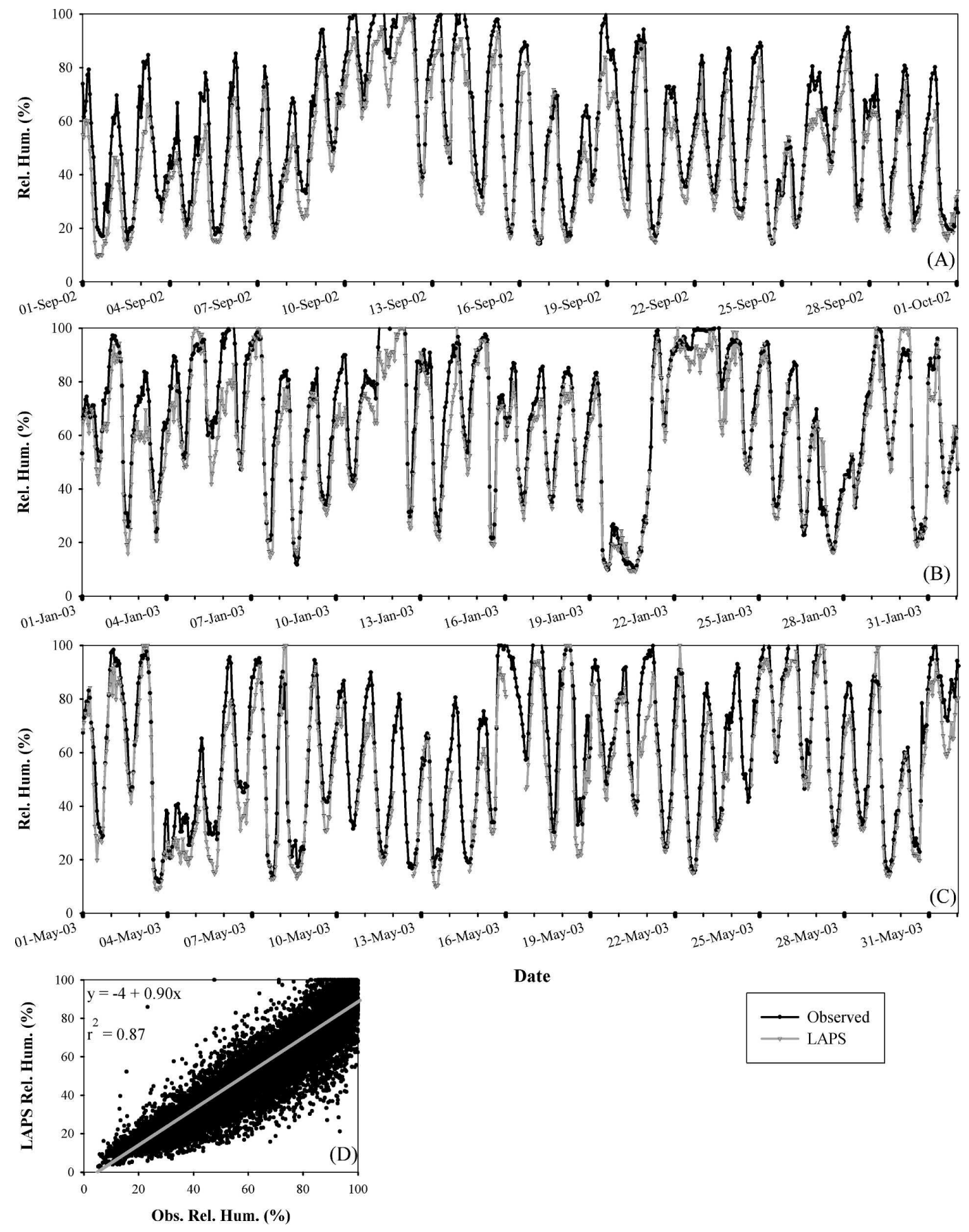

Date

FIG. 4. Same as Fig. 3 but for relative humidity.

lations and algorithms employed to capture the dynamics of air temperature appear to be successful within the validation domain (Figs. 1 and 2).

\section{2) Relative humidity}

Relative humidity values produced by LAPS closely matched concurrent observations (Fig. 4). As was the case with the temperature comparisons, temporal lags between the datasets were not apparent. September 2002, January 2003, and May 2003 (Figs. 4a-c) comparisons exhibited reasonable diurnal trends. However, LAPS relative humidity values were usually lower than observed data during observed minimums and maximums (Figs. 4a-c). 
The simple linear regression for the Vineland station revealed the relationship between LAPS and observed data. The proportion of variability in the LAPS data accounted for by the observations was $87 \%$, slope was 0.90 , the $y$ intercept was -4 , and moderate scatter of data points existed along the regression line, especially at higher observed humidity values (Fig. 4d). Like the temperature comparison, the relative humidity validation indicated that most of the variance between LAPS and observed data was explained in the linear model $\left(r^{2}\right.$ $=0.87)$. A slope $<1$ and a $y$ intercept $<0$ in the equation indicated that LAPS data tend to have a lower relative humidity than the observations. Moreover, the scatter of points around the regression line indicated that LAPS and observed data agreement was more probable at lower relative humidity values, and there is a higher chance of mismatch at higher $(>70 \%)$ relative humidity values.

The rmse and linear regressions of the relative humidity range were also typical of the other comparisons. LAPS relative humidity differed from observed data by $9 \%$. The diurnal magnitude of LAPS relative humidity values explained the variability in the observed range $53 \%$ of the time.

Relative humidity, in contrast to temperature, is less spatially continuous and can change dramatically over distances $<30 \mathrm{~km}$ (Hubbard 1994; Camargo and Hubbard 1999). Despite this relative humidity variability, the relationships between LAPS and observations were strong. Furthermore, it is likely that this high level of agreement is related to the successful representation of temperature. However, the discrepancy between LAPS and observed higher relative humidity values should be examined further.

\section{3) WIND SPEED}

LAPS and observed wind speed values were more divergent than temperature and relative humidity comparisons (Fig. 5). Overall, the LAPS data were more extreme than observations during the examined months (Figs. 5a-c). Lower observed wind speeds were coincident with higher LAPS wind speeds.

The simple linear regression performed on the Vineland LAPS and observation comparison revealed an intermediate variance agreement, a slope $<1$, a $y$ intercept close to 1 , and variable scatter along the regression line (Fig. 5d). The $r^{2}$ value for the wind speed regression indicated that $52 \%$ of the variation in the LAPS assimilation existed in the observed data. The slope value of 0.92 and a $y$ intercept of 1.1 revealed that LAPS overestimated wind speeds at low observed wind speeds while more closely matching higher wind speeds. Scatter around the regression line is relatively uniform up to $9 \mathrm{~m} \mathrm{~s}^{-1}$; it tapers at speeds above that due to the lower frequency of higher wind speeds in this location.

Like the other variables, Vineland wind speed rmse value and diurnal variation regressions were typical median values (Fig. 2). The mean difference between LAPS and observed wind speeds was $1.6 \mathrm{~m} \mathrm{~s}^{-1}$. The daily range of LAPS wind speeds explained the variation in observed ranges $38 \%$ of the time.

The erratic relationship between LAPS and the observed wind speed data is indicative of the spatial variability associated with wind speed (Hubbard 1994; Arya 2001). While winds are relatively consistent above the well-mixed daytime boundary layer, they interact with the surface and surface features (e.g., topography and vegetation) to produce spatially variable wind speeds, especially when observations were taken relatively close to the surface (i.e., $3 \mathrm{~m}$; Table 1). The potential influence of surface features on the relationship between LAPS and observed wind speeds is explored below (see section 4e).

\section{4) Precipitation}

The precipitation comparison showed the highest level of disagreement among the four compared meteorological variables (Fig. 6). In most cases, LAPS data showed evidence of precipitation where none was observed during the same period (Figs. 6a-c). When precipitation actually occurred, it was usually apparent in concurrent LAPS data.

Winter precipitation events were problematic (Fig. 6b) and noticeably absent from most of the observed meteorological datasets. The automated stations used in the validation lacked the appropriate equipment (nearly all had nonheated tipping buckets) for reliable hourly winter precipitation measurements, especially in the relatively cold and windy environments found in the study domain (Fig. 1). To address this limitation, winter precipitation observations were not considered in the statistical comparisons when they were recorded at temperatures $<3^{\circ} \mathrm{C}$.

The simple linear regression equation for Vineland's precipitation comparison revealed the explained variation, slope, $y$ intercept, and scatter along the regression line (Fig. 6d). The $r^{2}$ value from the regression indicated that $26 \%$ of the variance between the two datasets was explained by the equation. The slope was greater than 1 and the $y$ intercept was slightly greater than 0, indicating that LAPS assimilations generally overstated precipitation, especially at higher observed precipitation levels. There is abundant scatter along the regression line at lower observed $\left(<5 \mathrm{~mm} \mathrm{~h}^{-1}\right)$ precipitation levels (Fig. 6d). 

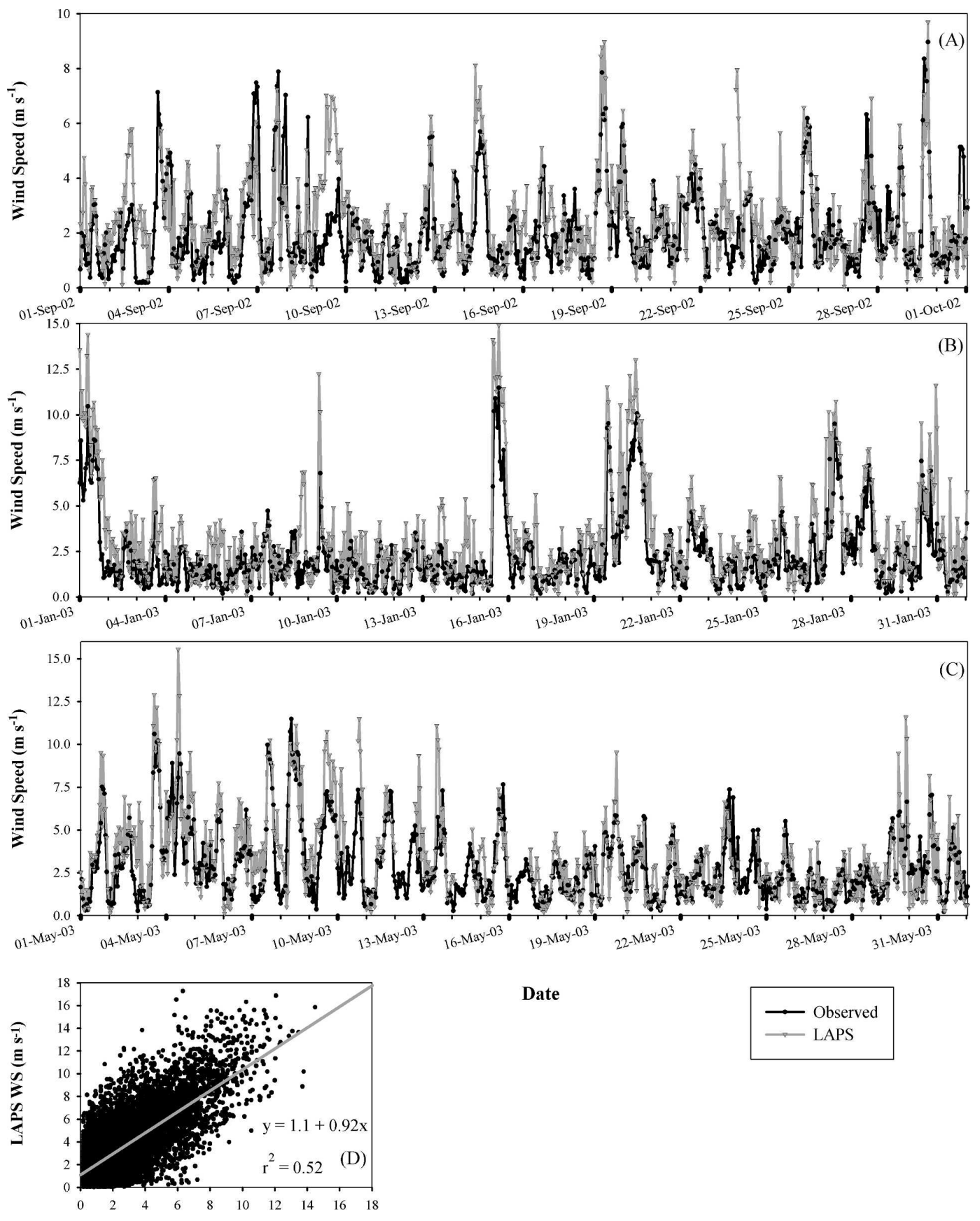

Date

Obs. WS (m s $\left.{ }^{-1}\right)$

FIG. 5. Same as Fig. 3 but for wind speed.

The disparity between LAPS and observed precipitation is likely a function of observational error, LAPS calculation of precipitation from radar data, and scaling differences. Precipitation measurements are some of the more difficult meteorological measurements to make accurately (Shih 1982; Ahrens 2003), especially when precipitation is accompanied by wind (Yang et al.
1998), which is a common occurrence in the study domain (Fig. 1). LAPS also calculates precipitation with the aid of radar observations that can over-/ underestimate precipitation (Brandes et al. 1999; Klazura et al. 1999; Legates 2000). LAPS precipitation discrepancies may be range dependent, where ground clutter at close range or beam overshooting at long 

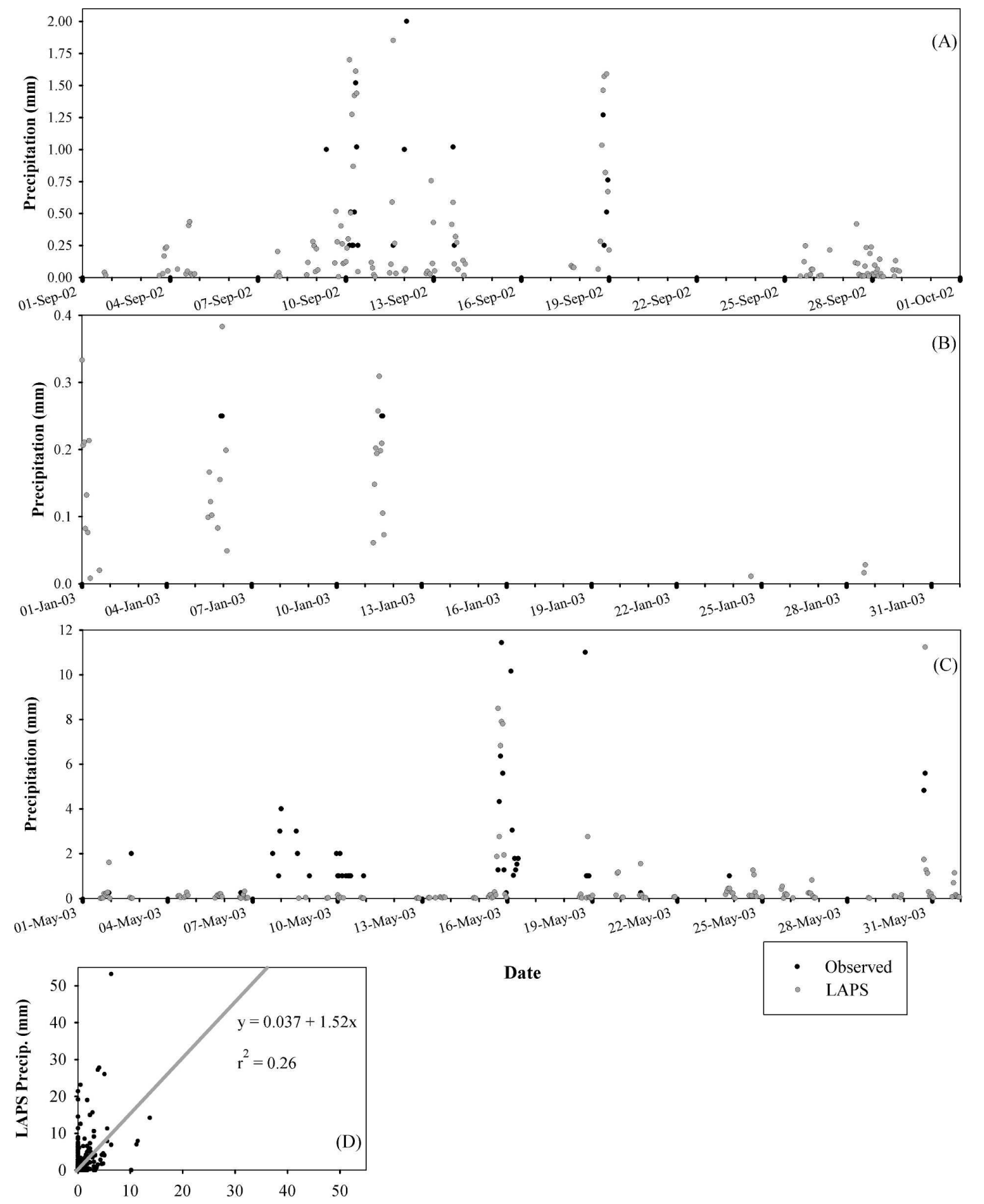

Date

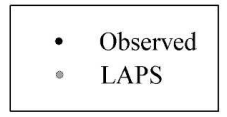

Obs. Precip (mm)

FIG. 6. Same as Fig. 3 but for precipitation. Because of tipping-bucket limitations, winter precipitation observations were not included unless temperatures were $>3^{\circ} \mathrm{C}$.

range produces errors (Henry 2003). Also, radar precipitation overestimates can occur relative to rain gauges for very light precipitation that evaporates before hitting the ground or fails to register in the rain gauges. Last, it is important to remember that the LAPS system studied here operates on a scale of 10 horizontal kilometers while the compared observations are point measurements located within that $10 \mathrm{~km}$. Precipitation amounts within that $10 \mathrm{~km} \times 10 \mathrm{~km}$ area may not be reflected by a point within that area, especially when precipitation is convective in origin (Pielke 2001), which is common in the study domain. 
TABLE 2. Regressions were performed analyzing the assessed meteorological variables' $r^{2}$, rmse, and range $r^{2}$ relationships with elevation and distance from the nearest LAPS-used meteorological data.

\begin{tabular}{|c|c|c|c|c|c|c|}
\hline Analysis factor & Equation $\left[Y=b_{0}+b_{1}(X)\right]$ & Std dev $b_{0}$ & Std dev $b_{1}$ & $\begin{array}{c}\text { Std dev } \\
\text { model (degrees } \\
\text { of freedom) }\end{array}$ & $r^{2}$ & $P$ value \\
\hline \multicolumn{7}{|c|}{ Elevation } \\
\hline \multicolumn{7}{|l|}{ Air temperature } \\
\hline$r^{2}$ & Elev $(\mathrm{m})=4480-3294$ temperature $r^{2}$ & 1059 & 1105 & $620(106)$ & 0.08 & $<0.01$ \\
\hline Rmse & Elev $(m)=557+390$ temperature rmse & 159 & 75 & $577(106)$ & 0.20 & $<0.001$ \\
\hline Range & Elev $(\mathrm{m})=2282-1523$ temperature range $r^{2}$ & 196 & 300 & $578(106)$ & 0.20 & $<0.001$ \\
\hline \multicolumn{7}{|c|}{ 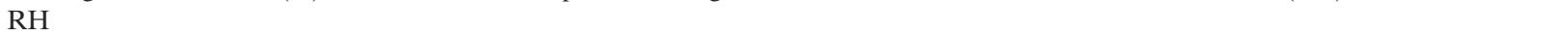 } \\
\hline$r^{2}$ & Elev $(m)=4065-3316 \mathrm{RH} r^{2}$ & 397 & 478 & $533(98)$ & 0.33 & $<0.001$ \\
\hline Rmse & Elev $(\mathrm{m})=2+143 \mathrm{RH}$ rmse & 152 & 16 & $476(98)$ & 0.47 & $<0.001$ \\
\hline Range & Elev $(\mathrm{m})=2486-2319 \mathrm{RH}$ range $r^{2}$ & 137 & 257 & $481(98)$ & 0.46 & $<0.001$ \\
\hline \multicolumn{7}{|c|}{ Wind speed (WS) } \\
\hline$r^{2}$ & $\operatorname{Elev}(\mathrm{m})=2585-2489 \mathrm{WS} r^{2}$ & 108 & 200 & $405(98)$ & 0.62 & $<0.001$ \\
\hline Rmse & Elev $(m)=-210+919$ WS rmse & 343 & 201 & $592(98)$ & 0.18 & $<0.001$ \\
\hline Range & Elev $(m)=2327-2749$ WS range $r^{2}$ & 126 & 321 & $492.4(98)$ & 0.43 & $<0.001$ \\
\hline \multicolumn{7}{|l|}{ Precipitation } \\
\hline$r^{2}$ & Elev $(m)=1331-449$ precipitation $r^{2}$ & 83 & 219 & $430(95)$ & 0.04 & $<0.05$ \\
\hline Rmse & Elev $(m)=1260-82.2$ precipitation rmse & 57 & 41 & $431(95)$ & 0.04 & $<0.05$ \\
\hline Range & Elev $(\mathrm{m})=1348-426$ precipitation range $r^{2}$ & 98 & 217 & $422(89)$ & 0.04 & $<0.05$ \\
\hline \multicolumn{7}{|c|}{ Distance from nearest used station } \\
\hline \multicolumn{7}{|c|}{ Air temperature } \\
\hline$r^{2}$ & Distance $(\mathrm{m})=34394-9695$ temperature $r^{2}$ & 31620 & 33001 & $18517(106)$ & 0.00 & 0.77 \\
\hline Rmse & Distance $(\mathrm{m})=17154+4025$ temperature rmse & 5050 & 2390 & $1879(106)$ & 0.03 & 0.10 \\
\hline Range & Distance $(\mathrm{m})=28810-5896$ temperature range $r^{2}$ & 6255 & 9578 & $18491(106)$ & 0.00 & 0.54 \\
\hline \multicolumn{7}{|c|}{ - } \\
\hline$r^{2}$ & Distance $(\mathrm{m})=62396-45050 \mathrm{RH} r^{2}$ & 13192 & 15870 & $17716(98)$ & 0.08 & $<0.01$ \\
\hline Rmse & Distance $(m)=8639+1793 \mathrm{RH}$ rmse & 5606 & 573 & $17571(98)$ & 0.09 & $<0.01$ \\
\hline Range & Distance $(\mathrm{m})=36898-23353 \mathrm{RH}$ range $r^{2}$ & 5081 & 9562 & $17895(98)$ & 0.06 & $<0.01$ \\
\hline \multicolumn{7}{|c|}{ Wind speed (WS) } \\
\hline$r^{2}$ & Distance $(\mathrm{m})=34407-18126 \mathrm{WS} r^{2}$ & 4837 & 8915 & $18056(98)$ & 0.04 & $<0.05$ \\
\hline Rmse & Distance $(\mathrm{m})=-2776+16714$ WS rmse & 10289 & 6034 & $17748(98)$ & 0.07 & $<0.01$ \\
\hline Range & Distance $(\mathrm{m})=34024-24161 \mathrm{WS}$ range $r^{2}$ & 4624 & 11767 & $18049(98)$ & 0.04 & $<0.05$ \\
\hline \multicolumn{7}{|c|}{ 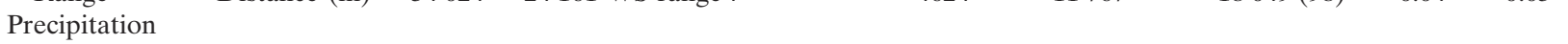 } \\
\hline$r^{2}$ & Distance $(\mathrm{m})=22252+8946$ precipitation $r^{2}$ & 3507 & 9273 & $18211(95)$ & 0.01 & 0.34 \\
\hline Rmse & Distance $(\mathrm{m})=26749-1834$ precipitation rmse & 2411 & 1734 & $18193(95)$ & 0.01 & 0.29 \\
\hline Range & Distance $(\mathrm{m})=21285+9856$ precipitation range $r^{2}$ & 4168 & 9289 & $18026(89)$ & 0.01 & 0.29 \\
\hline
\end{tabular}

\section{e. Station site characteristics}

\section{1) Elevation}

How did station elevation values influence the comparisons? Faint or no discernable relationships existed for elevation and comparison values associated with temperature and precipitation (Table 2). However, station elevation possessed a significant relationship with higher variance explained by regressions involving relative humidity $\left(r^{2}\right.$ values, rmse, and daily range $\left.r^{2}\right)$ and wind speed comparisons $\left(r^{2}\right.$ values and daily range $\left.r^{2}\right)$.

With an increase in elevation, $r^{2}$ values from the relative humidity simple linear regression comparisons decreased (Fig. 7a). The explanation in variance is intermediate with $33 \%$ of the variance in $r^{2}$ values explained by elevation (Table 2). Possible explanations for this trend include a paucity of higher-elevation meteorological observations used in LAPS, more complex terrain, background model limitations, and errors in LAPS dewpoint and temperature calculations. Another potential explanation involves the disparity in LAPS elevation values and actual station elevations. However, analyses (results not shown) indicated that the difference in LAPS and observed elevation did not explain the decrease in accuracy with elevation.

As the elevation of the observation location increased, regression $r^{2}$ values associated with LAPS and observed wind speed comparisons exhibited a marked decrease (Fig. 7b; Table 2). The 61\% explanation in variance due to elevation indicates that topographic features, forest cover, lack of observations, or some combination of these factors contributes to the higher 


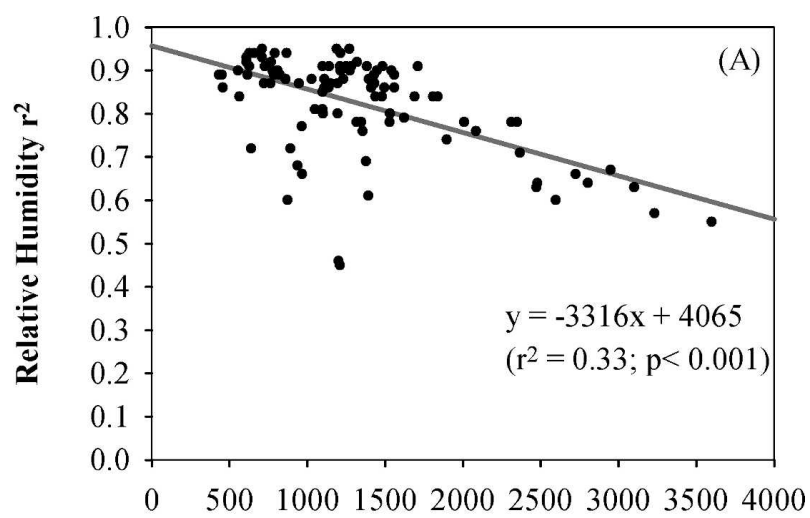

Station Elevation (m)

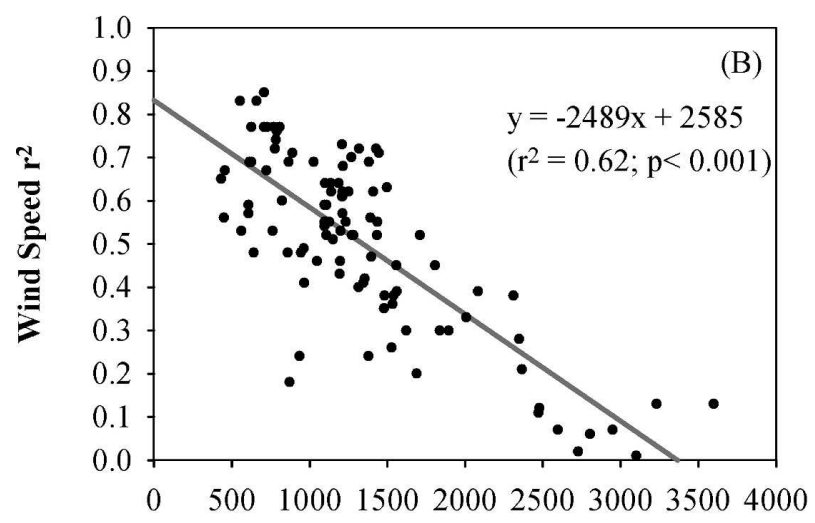

Station Elevation (m)

FIG. 7. (a) Relative humidity and (b) wind speed comparison $r^{2}$ values decrease with elevation (Table 2). The decrease with elevation may be related to local terrain influence, LAPS calculations, lack of local observations, or some combination of these factors.

frequency of disparities present between LAPS and observed wind speeds. Again, differences in $r^{2}$ values due to disparities between the $10-\mathrm{km}$ horizontal grid increment LAPS Digital Elevation Map and the observation station elevation were not significant with the magnitude of wind speed differences in LAPS and observed values.

\section{2) Distance From NeAREst LAPS-USED METEOROLOGICAL DATA}

Did observed and station proximity influence the comparisons? The distance from the nearest LAPSused station was employed as a predictor in linear regressions to examine its relationship to the direct comparison $r^{2}$, rmse, and daily range $r^{2}$ values (Table 2). Regressions were only significant for relative humidity and wind speed comparisons (Table 2), but the expla- nation of the variance for distance relative to the comparison measures was uniformly poor $\left(r^{2}\right.$ from 0.00 to $0.09)$. While the independent stations used for validation were located 1-69 km (mean $=25 \mathrm{~km})$ away from LAPS-used data stations, distance is not correlated to the identified relationships between observed and diagnosed meteorological values of temperature, relative humidity, wind speed, and precipitation.

\section{3) LAND COVER}

The 107 stations used for validation of LAPS assimilations were located in 13 different 1-km-aggregated National Land Cover classes (with quantity in parentheses): water (1), residential (2), urban (4), bare (1), deciduous forest (1), evergreen forest (2), shrubland (6), urban grassland (1), grassland (37), pasture/hay (15), small grain (14), row cropland (22), and alpine (1). According to the unbalanced one-way ANOVAs, $r^{2}$ values were significantly different among the landcover classes for temperature, relative humidity, and wind speed comparisons (Fig. 8; Table 3). The $r^{2}$ values among precipitation comparisons and cover classes were not significantly different.

How were the land cover types different with respect to accuracies among LAPS and observed data? Mean $r^{2}$ values of the temperature comparisons were all high with the exception of the residential cover class, which was identified as significantly lower (0.05 family error in a Tukey pairwise comparison) than the pasture/hay, grassland, row crop, small grain, and shrubland classes (Fig. 8a). While the relative humidity $r^{2}$ values were significantly different in the ANOVA (Table 3), Tukey pairwise comparisons using 0.05 and 0.10 family error rates failed to identify classes different from each other (Fig. 8b). With regard to wind speeds (Fig. 8c), evergreen $r^{2}$ values were significantly lower (0.05 family error) than grassland, small grains, row cropland, and urban classes. In addition, shrubland wind speed $r^{2}$ values were significantly lower than those associated with row crops.

It is important to note the disparity among landcover class memberships that were used to delineate these differences among land-cover types and LAPSobservation discrepancies. Stations associated with water, residential, urban, bare, deciduous forest, evergreen forest, urban grassland, and alpine classes possessed less than three members; results related to these classes should be treated with appropriate skepticism. It is not a matter of being attributed a false significance with respect to the $r^{2}$ differences; the Tukey test at a 0.05 family error rate is a conservative test (Neter et al. 1996). Rather, the error lies with classes that have a low sample size where stations having a high leverage were 


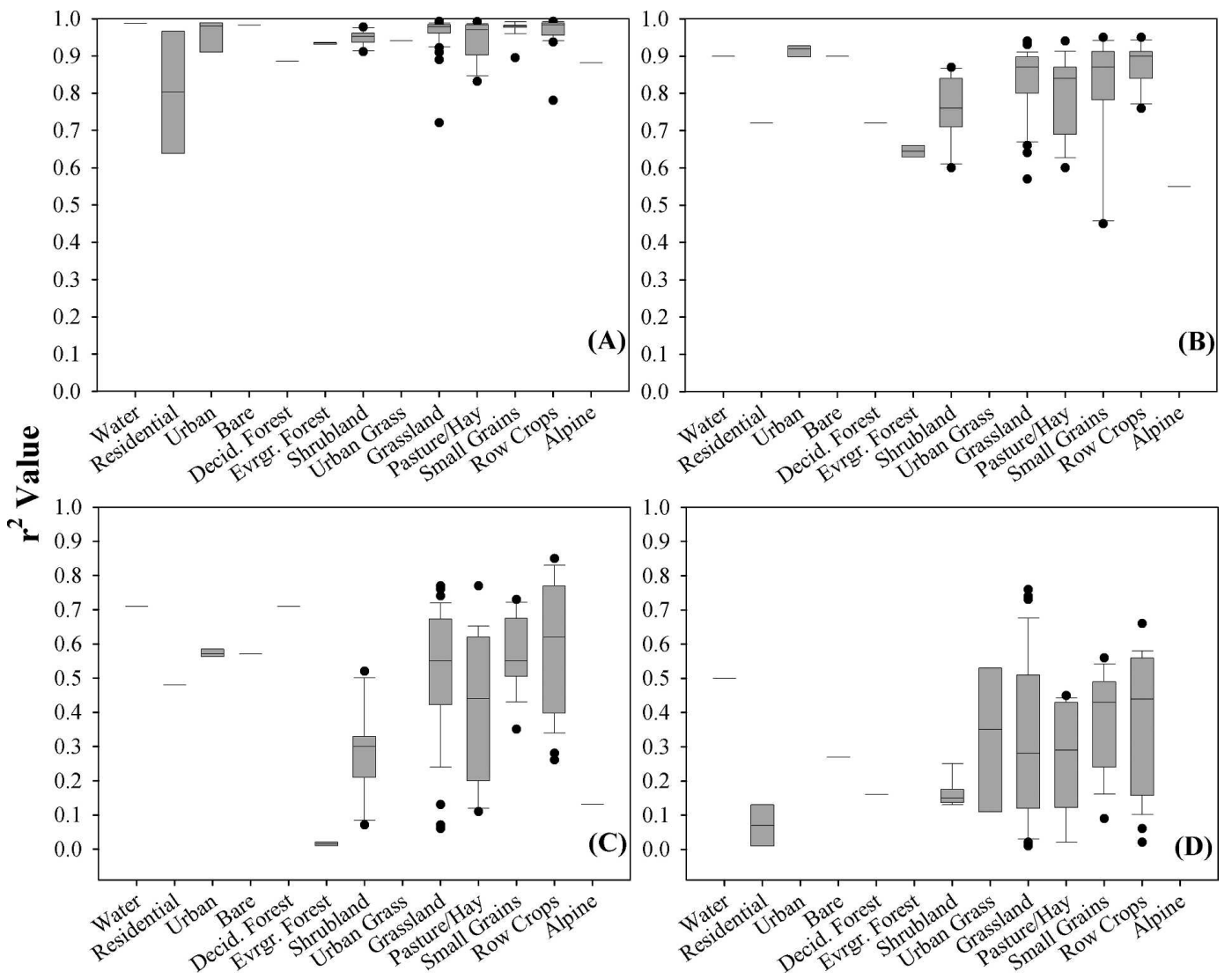

FIG. 8. The level of agreement ( $r^{2}$ value) varied significantly (Table 3$)$ with NLCD classes for (a) temperature, (b) relative humidity, and (c) wind speed. (d) No significant relationships existed between precipitation agreements and land cover. The box plots display the median (solid line), and 10th, 25th, 75th, and 90th percentiles of the $r^{2}$ values.

used to calculate the mean. For example, the $r^{2}$ values associated with the temperature comparisons of the residential class were 0.97 and 0.64 (Fig. 8a). The one station with the poorer 0.64 value made the residential class significantly different from the pasture/hay, grassland, row crop, small grain, and shrubland classes.

TABLE 3. One-way ANOVA results for effects of land cover on regression agreement $\left(r^{2}\right)$.

\begin{tabular}{lccccc}
\hline \hline Analysis & $\begin{array}{c}\text { Degrees of } \\
\text { freedom }\end{array}$ & $\begin{array}{c}\text { Sum of } \\
\text { squares }\end{array}$ & $\begin{array}{c}\text { Mean } \\
\text { square }\end{array}$ & $\begin{array}{c}F \\
\text { statistic }\end{array}$ & $P$ value \\
\hline $\begin{array}{l}\text { Air temperature } \\
\quad \text { Cover class }\end{array}$ & 12 & 0.07 & 0.01 & 2.33 & 0.01 \\
$\quad$ Error & 94 & 0.24 & 0.00 & & \\
RH & & & & & \\
$\quad$ Cover class & 11 & 0.30 & 0.03 & 2.56 & 0.01 \\
$\quad$ Error & 87 & 0.94 & 0.01 & & \\
$\begin{array}{l}\text { Wind speed } \\
\quad \text { Cover class }\end{array}$ & 11 & 1.36 & 0.12 & 3.92 & 0.0001 \\
$\quad$ Error & 87 & 2.74 & 0.03 & & \\
Precipitation & & & & & \\
$\quad$ Cover class & 9 & 0.40 & 0.04 & 1.11 & 0.36 \\
$\quad$ Error & 86 & 3.47 & 0.04 & & \\
\hline
\end{tabular}

With the lack of replications in mind, the most concrete land cover and accuracy relationship is associated with shrubland $r^{2}$ being lower than row crop $r^{2}$ values for the wind speed comparisons. Reasons for the disparity may be associated with weather differences among the land cover types or some other combination of characteristics (e.g., surface roughness).

\section{Conclusions}

LAPS assimilations matched trends in independent temperature and relative humidity observations temporally and spatially. In absolute terms, temperature differences between LAPS and observed data were generally $<2^{\circ} \mathrm{C}$, while relative humidity discrepancies were $9 \%$. Because LAPS relative humidity is derived from $T$ and $\mathrm{Td}$, the error magnitude appears to be consistent. Although less accurate, general diurnal changes in temperature and relative humidity were duplicated by LAPS regardless of land-cover type and elevation associated with the 107 stations employed in this project. Temperature and relative humidity characteristics 
were successfully characterized by LAPS for different landscapes (Figs. 7a and 7b). For example, mountain and grasslands, each with their distinctive surface characteristics, were represented by LAPS similarly.

Wind speed and precipitation relationships between LAPS and observed datasets were more variable and less reliable. Wind speeds were reasonably represented by LAPS assimilations and absolute accuracy was much higher for lower elevations. The main reason for disparities in precipitation values remains unknown but likely involves some combination of observation errors, scaling issues, and radar measurement limitations.

The LAPS system is a valuable and reliable choice for applications that require high temporal resolution and spatially distributed meteorological data. LAPS is a realistic data assimilation system; it extends the capabilities of its users to areas where few (if any) meteorological data sources exist or where those sources are often unreliable. Additionally, LAPS improvements underway (e.g., smaller horizontal resolution) are likely to extend the capabilities of this system and may help remedy relatively large disparities among precipitation estimates and observations.

Acknowledgments. We would like to acknowledge our sources of publicly available observational data: CLPX, COAGMET, GLOBE, HPRCC, and the South Dakota Office of Climatology. This project was funded under an NSF Grant 0222578, awarded to Drs. Graeme Stephens, Roger A. Pielke Sr., and Debra Krumm. Thanks are also due to Theresa Kay, John Smart, and four anonymous reviewers for providing many useful comments on this manuscript.

\section{REFERENCES}

Ahrens, C. D., 2003: Meteorology Today: An Introduction to Weather, Climate, and the Environment. 7th ed. Thomson/ Brooks/Cole, 624 pp.

Albers, S. C., 1995: The LAPS wind analysis. Wea. Forecasting, 10, 342-352.

— J. A. McGinley, D. L. Birkenheuer, and J. R. Smart, 1996: The Local Analysis and Prediction System (LAPS): Analyses of clouds, precipitation, and temperature. Wea. Forecasting, 11, 273-287.

Arya, S. P., 2001: Introduction to Micrometeorology. 2d ed. Academic Press, 420 pp.

Benjamin, S. G., G. A. Grell, J. M. Brown, T. G. Smirnova, and R. Bleck, 2004a: Mesoscale weather prediction with the RUC hybrid isentropic-terrain-following coordinate model. Mon. Wea. Rev., 132, 473-494.

—_, and Coauthors, 2004b: An hourly assimilation-forecast cycle: The RUC. Mon. Wea. Rev., 132, 495-518.

Birkenheuer, D., 1999: The effect of using digital satellite imagery in the LAPS moisture analysis. Wea. Forecasting, 14, 782-788.

Black, T. L., 1994: The new NMC mesoscale Eta Model: Description and forecast examples. Wea. Forecasting, 9, 265-278.
Brandes, E. A., J. Vivekanandan, and J. W. Wilson, 1999: A comparison of radar reflectivity estimates of rainfall from collocated radars. J. Atmos. Oceanic Technol., 16, 1264-1272.

Camargo, M. B. P., and K. G. Hubbard, 1999: Spatial and temporal variability of daily weather variables in sub-humid and semi-arid areas of the United States high plains. Agric. For. Meteor., 93, 141-148.

Cline, D., and Coauthors, 2002: Overview of the NASA Cold Land Processes Field Experiment (CLPX-2002). Proc. SPIE, 4894, 361-372.

Colorado Agricultural Meteorological Network, cited 2003: Automated weather data. [Available online at http://ccc. atmos.colostate.edu/ coagmet $/$.

Henry, A. E., 2003: Precipitation verification of the Local Analysis and Prediction System (LAPS) storm total precipitation estimates. Senior thesis, St. Cloud State University, St. Cloud, Minnesota, $17 \mathrm{pp}$.

Hubbard, K. G., 1994: Spatial variability of daily weather variables in the high plains of the USA. Agric. For. Meteor., 68, 29-41.

Jasper, K., J. Gurtz, and L. Herbert, 2002: Advanced flood forecasting in alpine watersheds by coupling meteorological observations and forecasts with a distributed hydrological model. J. Hydrol., 267, 40-52.

Kanamitsu, M., 1989: Description of the NMC Global Data Assimilation and Forecast System. Wea. Forecasting, 4, 335-342.

Klazura, G. E., J. M. Thomale, D. S. Kelly, and P. Jendrowski, 1999: A comparison of NEXRAD WSR-88D radar estimates of rain accumulation with gauge measurements for high- and low-reflectivity horizontal gradient precipitation events. $J$. Atmos. Oceanic Technol., 16, 1842-1850.

Lazarus, S. M., C. M. Ciliberti, J. D. Horel, and K. A. Brewster, 2002: Near-real-time applications of a mesoscale analysis system to complex terrain. Wea. Forecasting, 17, 971-1000.

Legates, D. R., 2000: Real-time calibration of radar precipitation estimates. Prof. Geogr., 52, 235-246.

Liston, G. E., and M. Sturm, 2002: Winter precipitation patterns in arctic Alaska determined from a blowing-snow model and snow-depth observations. J. Hydrometeor., 3, 646-659.

_ system (SnowModel). J. Hydrometeor., 7, 1259-1276.

_ high-resolution terrestrial modeling (MicroMet). J. Hydrometeor., 7, 217-234.

Loveland, T. R., B. C. Reed, J. F. Brown, D. O. Ohlen, Z. Zhu, L. Yang, and J. W. Merchant, 2000: Development of a global land cover characteristics database and IGBP DISCover from $1 \mathrm{~km}$ AVHRR data. Int. J. Remote Sens., 21, 1303-1330.

Ludwig, R., and W. Mauser, 2000: Modeling catchment hydrology within a GIS based SVAT-model framework. Hydrol. Earth Syst. Sci., 4, 239-249.

Marshall, C. H., R. A. Pielke, and L. T. Steyaert, 2004a: Has the conversion of natural wetlands to agricultural land increased the incidence and severity of damaging freezes in south Florida? Mon. Wea. Rev., 132, 2243-2258.

,,--- , and D. A. Willard, 2004b: The impact of anthropogenic land-cover change on the Florida peninsula sea breezes and warm season sensible weather. Mon. Wea. Rev., 132, 28-52.

McGinley, J. A., S. C. Albers, and P. A. Stamus, 1991: Validation of a composite convective index as defined by a real-time local analysis system. Wea. Forecasting, 6, 337-356. 
Minitab Inc, 2000: Minitab Statistical Software Version 13.32. Minitab Inc., State College, PA.

Mitchell, K. E., and Coauthors, 2004: The multi-institution North American Land Data Assimilation System (NLDAS): Utilizing multiple GCIP products and partners in a continental distributed hydrological modeling system. J. Geophys. Res., 109, D07S90, doi:10.1029/2003JD003823.

Neter, J., M. H. Kutner, C. J. Nachtsheim, and W. Wasserman, 1996: Applied Linear Statistical Models. 4th ed. Irwin, 1408 pp.

Parton, W. J., M. Hartman, D. Ojima, and D. Schimel, 1998: DAYCENT and its land surface submodel: Description and testing. Global Planet. Change, 19, 35-48.

Peet, R. K., 2000: Forests and meadows of the Rocky Mountains. North American Terrestrial Vegetation, 2d ed., M. G. Barbour and W. D. Billings, Eds., Cambridge University Press, 75121.

Pielke, R. A., 2001: Influence of the spatial distribution of vegetation and soils on the prediction of cumulus convective rainfall. Rev. Geophys., 39, 151-177.

—, and P. Mehring, 1977: Use of mesoscale climatology in mountainous terrain to improve spatial representation of mean monthly temperatures. Mon. Wea. Rev., 105, 108-112.

— , T. Stohlgren, W. Parton, N. Doesken, J. Moeny, L. Schell, and K. Redmond, 2000: Spatial representativeness of temperature measurements from a single site. Bull. Amer. Meteor. Soc., 81, 826-830.

and Coauthors, 2002: Problems in evaluating regional and local trends in temperature: An example from eastern Colorado, USA. Int. J. Climatol., 22, 421-434.

G. Marland, R. A. Betts, T. N. Chase, J. L. Eastman, J. O. Niles, D. Niyogi, and S. W. Running, 2003: The influence of land-use change and landscape dynamics on the climate system: Relevance to climate-change policy beyond the radiative effect of greenhouse gases. Capturing Carbon and Conserving Biodiversity: The Market Approach, I. R. Swingland, Ed., Earthscan Publications, 157-172.
Rodell, M., and Coauthors, 2004: The Global Land Data Assimilation System. Bull. Amer. Meteor. Soc., 85, 381-394.

Running, S. W., and J. C. Coughlan, 1988: A general-model of forest ecosystem processes for regional applications. 1. Hydrologic balance, canopy gas-exchange and primary production processes. Ecol. Model., 42, 125-154.

Scuderi, L. A., C. B. Schaaf, K. U. Orth, and L. E. Band, 1993: Alpine treeline growth variability: Simulation using an ecosystem process model. Arct. Alp. Res., 25, 175-182.

Shih, S. F., 1982: Rainfall variation analysis and optimization of gauging systems. Water Resour. Res., 18, 1269-1277.

Sims, P. L., and P. G. Risser, 2000: Grasslands. North American Terrestrial Vegetation, 2d ed., M. G. Barbour and W. D. Billings, Eds., Cambridge University Press, 323-356.

Thornton, P. E., S. W. Running, and M. A. White, 1997: Generating surfaces of daily meteorology variables over large regions of complex terrain. J. Hydrol., 190, 214-251.

Vogelmann, J. E., S. M. Howard, L. M. Yang, C. R. Larson, B. K. Wylie, and N. Van Driel, 2001: Completion of the 1990s National Land Cover Data Set for the conterminous United States from Landsat Thematic Mapper data and ancillary data sources. Photogramm. Eng. Remote Sensing, 67, 650652.

Westrick, K. J., P. Storck, and C. F. Mass, 2002: Description and evaluation of a hydrometeorological forecast system for mountainous watersheds. Wea. Forecasting, 17, 250-262.

Whitaker, A., Y. Alila, J. Beckers, and D. Toews, 2003: Application of the Distributed Hydrological Soil Vegetation Model to Redfish Creek, British Columbia: Model evaluation using internal catchment data. Hydrol. Processes, 17, 199-224.

Winstral, A., K. Elder, and R. E. Davis, 2002: Spatial snow modeling of wind-redistributed snow using terrain-based parameters. J. Hydrometeor., 3, 524-538.

Yang, D. Q., B. E. Goodison, J. R. Metcalfe, V. S. Golubev, R. Bates, T. Pangburn, and C. L. Hanson, 1998: Accuracy of NWS 8" standard nonrecording precipitation gauge: Results and application of WMO intercomparison. J. Atmos. Oceanic Technol., 15, 54-68. 